\title{
Rapid Characterization of Virulence Determinants in Helicobacter pylori Isolated from Non-Atrophic Gastritis Patients by Next-Generation Sequencing
}

\author{
Frank Imkamp ${ }^{1, \dagger}{ }^{,}$Francis N. Lauener ${ }^{1, \dagger}{ }^{\dagger}$ Daniel Pohl ${ }^{2}$, Philippe Lehours ${ }^{3,4}{ }^{\oplus}$, Filipa F. Vale ${ }^{5}$, \\ Quentin Jehanne $^{4}$, Reinhard Zbinden ${ }^{1}$, Peter M. Keller ${ }^{1, \ddagger}$ (D) and Karoline Wagner ${ }^{1, *, \S}$ \\ 1 Institute of Medical Microbiology, University of Zurich, 8006 Zurich, Switzerland \\ 2 Gastroenterology Division, University Hospital of Zurich, 8006 Zurich, Switzerland \\ 3 INSERM UMR1053, Bordeaux Research in Translational Oncology, BaRITOn, Université de Bordeaux, \\ 33076 Bordeaux, France \\ 4 French National Reference Centre for Campylobacter and Helicobacter, Bordeaux Hospital, \\ 33076 Bordeaux, France \\ 5 Host-Pathogen Interactions Unit, Research Institute for Medicine (iMed-ULisboa), Faculdade de Farmácia, \\ Universidade de Lisboa, 1649-003 Lisboa, Portugal \\ * Correspondence: karoline.wagner@usb.ch \\ $+\quad$ F.I. and F.N.L. contributed equally to the manuscript. \\ $\ddagger$ Current affiliation: Institute for Infectious Diseases, University of Bern, 3001 Bern, Switzerland. \\ $\S$ Current affiliation: University Hospital of Basel, Petersgraben 4, 4031 Basel, Switzerland.
}

Received: 28 June 2019; Accepted: 9 July 2019; Published: 12 July 2019

Abstract: Helicobacter pylori is a major human pathogen that causes a wide range of gastrointestinal pathology. Progression of $H$. pylori induced gastritis to more severe disease has been found to highly correlate with the array of virulence factors expressed by the pathogen. The objective of this study was twofold: first, to characterize the genetic diversity of H. pylori strains isolated from 41 non-atrophic gastritis patients in Switzerland, an issue that has not been investigated to date. And second, to assess the prevalence and sequence variation of $H$. pylori virulence factors (cag $A$, vac $A$, ice $A$ and $d u p A$ ) and genes encoding outer membrane proteins (OMPs; $b a b A, b a b B, s a b A, s a b B, h o p Z$, hopQ and $\operatorname{oip} A$ ) by whole genome sequencing (WGS) using an Illumina MiSeq platform. WGS identified high genetic diversity in the analyzed $H$. pylori strains. Most $H$. pylori isolates were assigned to hpEurope $(95.0 \%, 39 / 41)$, and the remaining ones $(5.0 \%, 2 / 41)$ to hpEastAsia, subpopulation hspEAsia. Analysis of virulence factors revealed that $43.9 \%$ of the strains were cagA-positive, and the vacA s1 allele was detected in $56.0 \%$ of the isolates. The presence of $\operatorname{cag} A$ was found to be significantly associated $(P<0.001)$ with the presence of vac $A$ s1, babA2 and hop $Q$ allele 1 as well as expression of oipA. Moreover, we found an association between the grade of gastritis and $H$. pylori abundance in the gastric mucosa, respectively and the presence of $c a g A$, vac $A$ s1 and hop $Q$ allele 1 . Among our 41 gastritis patients, we identified seven patients infected with $H$. pylori strains that carried a specific combination of virulence factors (i.e., $c a g A, v a c A$ s1 allele and $b a b A 2$ allele), recently implicated in the development of more severe gastrointestinal pathology, like peptic ulcer disease and even gastric cancer. To this end, WGS can be employed for rapid and detailed characterization of virulence determinants in $\mathrm{H}$. pylori, providing valuable insights into the pathogenic capacity of the bacterium. This could ultimately lead to a higher level of personalized treatment and management of patients suffering from $H$. pylori associated infections.

Keywords: Helicobacter pylori; next generation sequencing; virulence; gastritis; cag $A$; vac $A$; ice $A$; dupA; babA; babB; sabA; sabB; hopZ; hopQ; oipA 


\section{Introduction}

Helicobacter pylori is a major human pathogen that causes chronic inflammation of the gastric mucosa. While the majority of infected individuals remain asymptomatic, some develop severe gastrointestinal pathology like peptic ulcer disease (10-20\%) or even gastric cancer (1-2\%) [1,2].

Previous studies have shown that $H$. pylori strains display different degrees of virulence that determine their pathogenicity and potential progression of disease $[3,4]$. Understanding the factors that affect the progression of asymptomatic $H$. pylori infection to clinical disease is of utmost importance for efficient patient management.

The $H$. pylori genome encodes several potential virulence factors. One of the most important, the cytotoxin-associated gene $(\operatorname{cag} A)$ has been associated with mucosal inflammation and a more severe clinical outcome of $H$. pylori-associated infection [5]. The cytotoxin encoded by the vacuolating cytotoxin gene (vacA) damages epithelial cells by formation of vacuoles, initiates a proinflammatory response and specifically inhibits T-cell activation and proliferation [6,7]. VacA secretion by H. pylori has been reported to manipulate the autophagy pathway of its host, thereby facilitating intracellular survival and persistence of $H$. pylori in the gastric mucosa [8]. Although all H. pylori strains harbor vacA, sequence variations at the signal region (s1a, s1b and s2) and the middle region ( $\mathrm{m} 1$ and $\mathrm{m} 2)$ of the gene are associated with different levels of vacuolating activity of the encoded cytotoxin. Specifically, strains carrying $v a c A \mathrm{~s} 1 \mathrm{a} / \mathrm{m} 1$ exhibit more cytotoxic activity than strains with $v a c A \mathrm{~s} 1 \mathrm{~b} / \mathrm{m} 1$, whereas $v a c A \mathrm{~s} 2 / \mathrm{m} 2$ is not associated with any cytotoxic activity $[3,9]$. Another putative virulence factor present in virtually all $H$. pylori strains is encoded by iceA, which occurs in two allelic forms, namely iceA1 and iceA2 [10]. Expression of $i c e A 1$ is upregulated upon contact of $H$. pylori with human gastric epithelial cells and has been associated with peptic ulcer disease $[10,11]$. In contrast, iceA2 seems to not be involved in gastrointestinal pathology. Another marker indicative for the risk of gastric cancer development is the duodenal ulcer-promoting gene $(d u p A)$, which induces proinflammatory cytokine secretion by mononuclear cells [12-14]. H. pylori strains containing $d u p A$ have been associated with a reduced risk of developing gastric atrophy and gastric cancer compared to strains lacking this gene $[15,16]$.

At the initiation of the infection process, $H$. pylori adheres to the gastric mucosa and mediates a gastric inflammatory response. More than 30 outer membrane proteins (OMPs) have been identified in H. pylori, and most of them are involved in bacterial adherence [17]. Production of OMPs is either regulated through recombination (gene conversion) or by slipped strand mispairing (phase variation) within CT dinucleotide repeat regions located at the 5 -end of the respective gene [17,18]. Important OMPs that potentially determine H. pylori pathogenicity are SabA, SabB, BabA, BabB, OipA, HopZ and HopQ. Expression of these OMPs may contribute to gastrointestinal disease by mediating $H$. pylori adherence, enhancing the activity of the cag-pathogenicity island, influencing $H$. pylori-induced signaling in host cells, or stimulating proinflammatory immune responses (e.g., $[19,20])$.

Virulence of H. pylori is commonly determined by targeted polymerase chain reaction (PCR) amplification of the genes mentioned above. However, this approach has serious drawbacks. First, multiple PCR reactions are needed to cover all known virulence genes and their variants, making a thorough characterization of $H$. pylori isolates cumbersome. Second, PCR amplification of the target region may be impaired, when mismatches occur in the primer binding sites. Moreover, high numbers of PCR amplification cycles may lead to artifacts in the amplified target sequence, potentially leading to wrong assumptions regarding the presence or structural variation of OMPs. In contrast, whole genome sequencing (WGS) enables relatively fast deep sequencing of bacterial genomes, and thus, is increasingly used in molecular diagnostics. Genomic information gained by WGS can be used to investigate bacterial antibiotic resistance (based on resistance genes and drug resistance mutations) and bacterial diversity and pathogenicity (based on the presence and expression of virulence factors identified in the bacterial genome). Only recently, we have described the clinical use of WGS for the prediction of drug resistance phenotypes in H. pylori [21].

In this follow-up study, we aimed to demonstrate that WGS data of H. pylori isolates also allows for a rapid characterization of virulence factors and the assessment of a strain's pathogenic capacity. Since 
the frequency of virulence determinants in $H$. pylori, and their association with clinically relevant gastric disease appears to vary considerably between different geographic regions, we aimed to determine the frequency of virulence factors ( $c a g A, v a c A$, ice $A$ and $d u p A)$ and genes encoding OMPs ( $b a b A, b a b B$, sabA, $s a b B$, hop $Q$, hopZ and oipA) in Swiss patients suffering from non-atrophic gastritis.

\section{Materials and Methods}

\subsection{Histology of Gastric Biopsy Specimens}

Gastric antral and corpus specimens were taken with single-use forceps biopsy in accordance with the Sydney system [22]. Specifically, specimens were obtained from the lesser and greater curvature within maximum $3 \mathrm{~cm}$ of the pylorus, from the lesser curvature approximately $4 \mathrm{~cm}$ proximal to the angulus, from the middle lesser curvature (corpus) and incisura angularis. Formalin-fixed paraffin-embedded biopsies were cut with $2 \mathrm{~mm}$ thickness and routinely processed using staining with eosin/hematoxylin dye (Tissue-Tek Prisma ${ }^{\mathrm{TM}} 1$, Sakura, Netherlands). Standard Giemsa staining was performed for assessment of $H$. pylori infection (Tissue-Tek Prisma ${ }^{\mathrm{TM}} 2$ ). Quantitative and qualitative grading of gastritis was performed using the Sydney criteria: H. pylori positive/absent, presence of neutrophils and mononuclear cells, atrophy of antrum and/or corpus, presence of intestinal metaplasia [22]. Gastritis was graded as mild, moderate or marked, and the abundance of $H$. pylori was classified in the gastric biopsy specimens as few/some $(+)$, abundant $(++)$ and highly abundant (+++; Table S1).

\subsection{Clinical H. pylori Isolates, Culture Methods and Phenotypic Drug Susceptibility Testing}

H. pylori was isolated from multiple gastric antral and corpus biopsy specimens sent to the Institute of Medical Microbiology (IMM), University of Zurich, between January 2013 and December 2017 for culture-based phenotypic drug susceptibility testing (DST) after failed H. pylori eradication therapy.

Clinical eradication was defined as a negative urea breath test or clinical impression of cure (symptom relief) on follow up assessments. Eradication therapy failure was defined as persistent positive urea breath test, repeat biopsy, or persistence of symptoms of dyspepsia in follow up assessments.

For this study, $41 \mathrm{H}$. pylori strains were incubated on in-house produced Brucella agar plates (with $5 \%$ horse blood) for 3 days at $37^{\circ} \mathrm{C}$ under microaerobic conditions $\left(90 \% \mathrm{~N}_{2}, 5 \% \mathrm{CO}_{2}, 5 \% \mathrm{O}_{2}\right)$ using a gas generator (CampyGen, Thermo Scientific, Waltham, MA, USA). After 3 days, single H. pylori colonies were subcultured on Brucella agar plates and then stored at $-80^{\circ} \mathrm{C}$ in $3 \%$ skim milk (Difco Laboratories, Detroit, USA) supplemented with $5 \%$ glucose (Difco Laboratories). H. pylori isolates were stored at $-80^{\circ} \mathrm{C}$ in the bacterial strain collection of the IMM. In this study, H. pylori culture was done to perform culture-based phenotypic DST and DNA extraction for WGS.

H. pylori cultures were adjusted to a McFarland standard of 3 [23]. Phenotypic DST was performed on Mueller Hinton agar plates containing 5\% horse blood (bioMérieux), using the following E-Tests ${ }^{\circledR}$ (bioMérieux): amoxicillin $(0.016-256 \mathrm{mg} / \mathrm{L})$, clarithromycin $(0.016-256 \mathrm{mg} / \mathrm{L})$, metronidazole $(0.016-256 \mathrm{mg} / \mathrm{L})$, levofloxacin $(0.016-32 \mathrm{mg} / \mathrm{L})$, rifampicin $(0.016-32 \mathrm{mg} / \mathrm{L})$ and tetracycline $(0.016-32 \mathrm{mg} / \mathrm{L})$. Agar plates were incubated under microaerobic conditions at $37^{\circ} \mathrm{C}$ for 3 days. Subsequently, MICs were determined by analysing the agar plates using a light microscope (Leica M80, Leica Microsystems, Heerbrugg, Switzerland). Susceptibility interpretation was performed according to the European Committee on Antimicrobial Susceptibility Testing (EUCAST) [24], except for rifampicin for which the susceptibility interpretation (MIC: $S \leq 4 ; R>4$ ) was done according to Hays et al. [25] and the Comité de l'Antibiogramme de la Société Française de Microbiologie (CASFM)/EUCAST recommendations for H. pylori [26].

\subsection{DNA Extraction, Library Preparation and Sequencing of H. pylori Strains}

DNA extraction from H. pylori cultures was performed with the DNeasy ${ }^{\circledR}$ UltraClean ${ }^{\circledR}$ Microbial kit (Qiagen, Hilden, Germany), following the manufacturer's recommendations. Library preparation 
was done using the Qiagen ${ }^{\circledR}$ QIAseq FX DNA kit (Qiagen, Hilden, Germany), according to the manufacturer's recommendations with 6 min of fragmentation time. Sequencing library quality and size distribution (range of $300 \mathrm{bp}$ to $700 \mathrm{bp}$; median of $500 \mathrm{bp}$ ) was analyzed on a fragment analyzer automated CE system (Advanced Analytical Technologies Inc., Heidelberg, Germany), according to the manufacturer's instructions using the fragment analyzer 474 HS NGS kit. Sequencing libraries were pooled in equimolar concentrations and paired-end sequenced $(2 \times 150 \mathrm{bp})$ on an Illumina MiSeq platform (Illumina ${ }^{\circledR}$, San Diego CA, USA).

\subsection{Bioinformatic and Statistical Analysis}

Raw sequencing reads (fastq) were filtered and trimmed using the FASTQ trimmer tool of the FASTX-Toolkit (Hannon Lab, Cold Spring Harbour Laboratories) applying a threshold PHRED score of 25. In order to detect the presence and variants of different virulence genes, fastq files were analyzed using the ARIBA pipeline [27], querying a custom-made database of gene sequences derived from H. pylori strains available in the NCBI database (https://www.ncbi.nlm.nih.gov; Table S2). Contingency analysis was performed using the chi-square test $\left(X^{2}\right)$ of independence. A level of $p<0.05$ was considered statistically significant. Statistics and data visualization was done in $\mathrm{R}$ [28].

\subsection{Genotyping and Phylogenetic Analysis}

Phylogeography and population assignment was performed on the basis of seven housekeeping genes (atpA, efp, trpC, ppa, mutY, yphC and ureI). Each gene sequence was extracted from the WGS data of the $41 \mathrm{H}$. pylori strains using standard nucleotide BLAST. Additionally, $315 \mathrm{H}$. pylori strains with known origins available at PubMLST (http://pubmlst.org/helicobacter/), originally described by Falush et al. [29] were included in the analysis. A multi FASTA file was created, containing the concatenation of the seven housekeeping genes for each $H$. pylori strain. Sequences were aligned using the MUSCLE alignment algorithm. Newick tree format was generated using the neighbor -joining algorithm of the MEGA software [30], and a phylogenetic tree was constructed using the iTOL platform (https://itol.embl.de) (Figure 1). In addition, for each housekeeping gene, one multi FASTA file was created. Alleles of these 7 genes were aligned using MUSCLE. Alignment results were merged into one file and converted to the input format of STRUCTURE using xmfa2struct tool (Xavier Didelot, University of Warwick, Coventry, UK). Population assignment of the $41 \mathrm{H}$. pylori strains was performed with STRUCTURE [31,32], using the "no admixture model" and the 315 strains of PubMLST as training isolates ( $K=20,000$ iterations and a burn-in period of 20,000 iterations). Furthermore, the "admixture model" of STRUCTURE was performed to estimate the proportion of introgression from other populations in similar conditions. Finally, the subpopulation of hpEastAsia isolates were determined using the "no admixture model" of STRUCTURE and 121 strains from hpEastAsia populations (21 hspAmeridin, $50 \mathrm{hspEAsia}$ and $50 \mathrm{hspMaori)}$ from pubMLST as training isolates ( $K=3$ and 20,000 iterations and a burn-in period of 20,000 iterations).

\subsection{Ethics Approval, Consent to Participate and Consent for Publication}

The study was conducted according to good laboratory practice and in accordance with the Declaration of Helsinki and national and institutional standards. The Swiss act on medical research involving human subjects does not apply to this study as solely bacterial strains and anonymized patient-related data were used in this study. Thus, no consent for publication is required. 


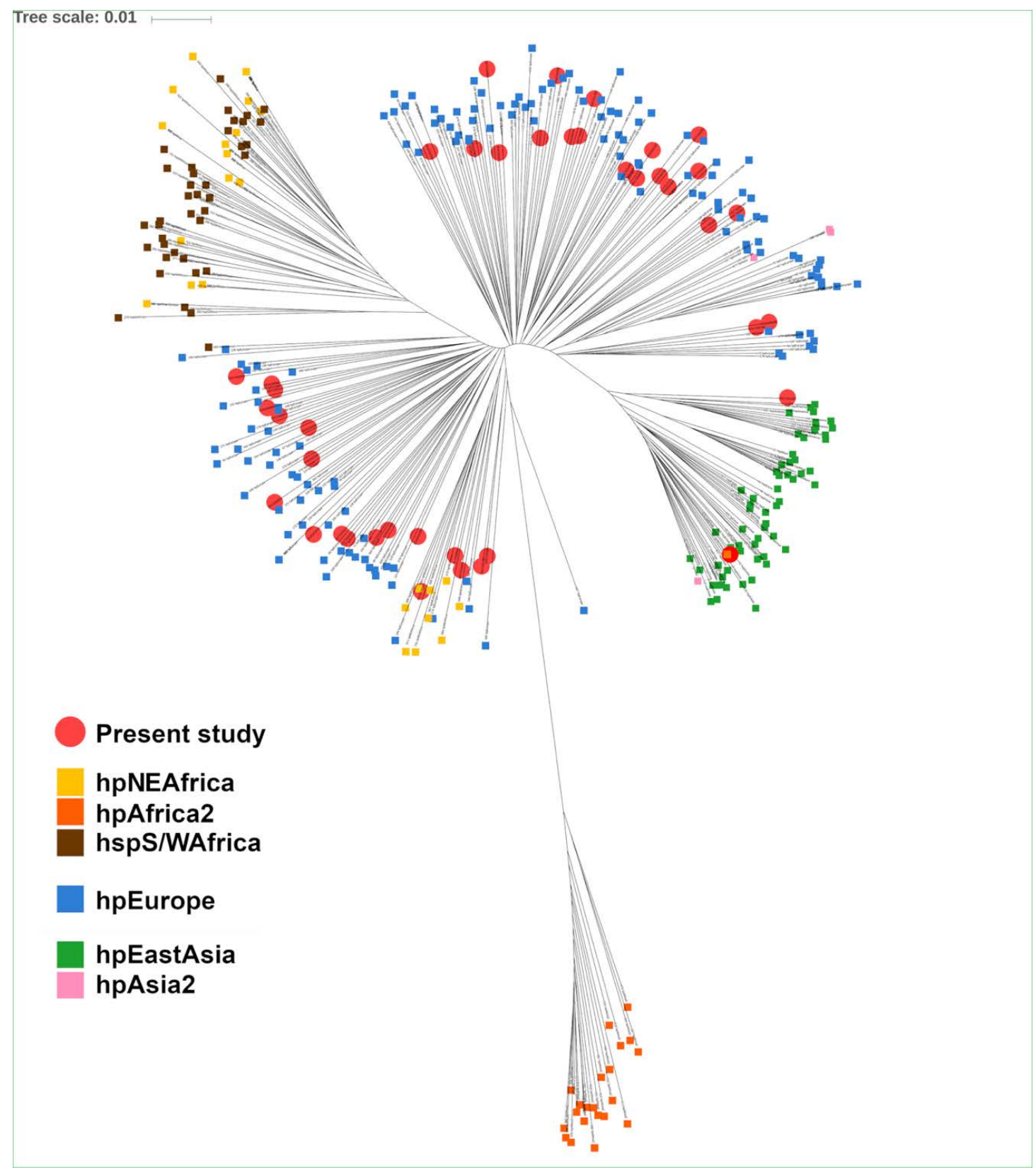

Figure 1. Phylogenetic analysis of the $41 \mathrm{H}$. pylori strains isolated from non-atrophic gastritis patients (Neighbor-joining tree-Kimura 2-parameter). Isolates representative of $H$. pylori populations are identified with colored squares and were retrieved from PubMLST. H. pylori isolates included in the present study are highlighted with red circles, and cluster mainly (95\%) with hpEurope, but also with hpEastAsia (5\%).

\section{Results and Discussion}

\subsection{Patient Demographics and H. pylori Epidemiology}

The patients' demographics are summarized in Table 1. Secondary antibiotic resistance to clarithromycin and metronidazole, two antibiotics commonly used in empiric $H$. pylori eradication regimens, was high ( $85 \%$ and $73 \%$; Table 1). The high drug resistance rate is to be expected given the "test-and-treat" strategy employed in Switzerland that only recommends endoscopy and culture-based phenotypic DST after a failed H. pylori eradication attempt [33]. Resistance to levofloxacin was $29 \%$ and to rifampicin $2 \%$, whereas no resistance to tetracycline and amoxicillin was observed. 
Table 1. Display of the epidemiological data of the patient population and drug resistance in $H$. pylori isolates.

\begin{tabular}{ccc}
\hline Age (years) & Mean & $45 \pm 15$ \\
& Range & $17-81$ \\
\hline \multirow{2}{*}{ Sex (Count) } & Female & 25 \\
& Male & 16 \\
\hline Ethnicity (Count) & African & 2 \\
& Caucasian & 36 \\
& Chinese & 1 \\
& Hispanic & 2 \\
Gastritis (Count) & Mild & 3 \\
& Moderate & 27 \\
\hline Helicobacter pylori & Marked & 11 \\
in gastric biopsy & Few/Some (+) & 9 \\
(Count) & Abundant (++) & 18 \\
& Highly Abundant (+++) & 14 \\
\hline Drug-resistant & Amoxicillin & 0 \\
Helicobacter pylori & Clarithromycin & 35 \\
(Count) & Metronidazole & 30 \\
& Levofloxacin & 12 \\
& Rifampicin & 1 \\
& Tetracycline & 0 \\
\hline
\end{tabular}

Some H. pylori strains were resistant to multiple antibiotics (Table S1). Patient's age did not correlate with increased antibiotic resistance in $H$. pylori $(P>0.05)$ as has been recently described for clarithromycin resistance in Mycoplasma sp. [34].

Most of the $41 \mathrm{H}$. pylori isolates were assigned to hpEurope, matching host ethnicity and the geographical area of $H$. pylori isolation. Additionally, hpEurope isolates showed scarce signs of introgression from hpAfrica1, which is consistent with Central European H. pylori isolates, supporting previous observations [35,36]. The remaining two isolates were assigned to hpEastAsia, subpopulation hspEAsia (Figure 1). Interestingly these strains were isolated from a Chinese and a Hispanic patient, respectively. While the former presented no signs of introgression from other populations, the latter displayed evidence of introgression from hpEurope, which agrees with the admixture pattern frequently found in Latin American isolates [35,36].

\subsection{Presence of Virulence Determinants in H. pylori Isolates}

A comprehensive characterization of the $41 \mathrm{H}$. pylori isolates was done based on WGS data. First, we focused on virulence-associated genes, namely cagA, vacA, ice A and dupA. Out of $41 \mathrm{H}$. pylori strains, $19(46.3 \%)$ carried the cag $A$ gene (Figure 2). The importance of determining the presence of $c a g A$ in clinical $H$. pylori isolates is underlined by previous studies that have consistently reported a higher risk for the development of premalignant lesions and even gastric cancer in patients infected with cagA-positive H. pylori strains (e.g., [37-39]). The number of cagA-positive H. pylori strains differs by geographic region, such as $60.0 \%$ in adult gastritis patients in Germany [39], 47.1\% in the Netherlands [11], 66.0\% in Finnish gastritis patients [40], 66.0\%, 49.7\% and 55.6\% in France, Italy and Portugal, respectively [37,41,42], and $50.0 \%$ to $83.0 \%$ in Eastern European adult gastritis patients [38,43,44]. In the present study, the number of $H$. pylori strains carrying cagA $(N=19 ; 46.3 \%)$ closely relates to rates reported from these studies and agrees well with the ethnicity of the patient population, of which the majority has a Caucasian origin.

The majority of $H$. pylori isolates $(23 / 41 ; 56 \%)$ harbored the vacA s1 allele. Specifically, the vacA s1a allele was detected in $15 / 41(36.6 \%)$ H. pylori strains $(7 \mathrm{~s} 1 \mathrm{a} / \mathrm{m} 1,8 \mathrm{~s} 1 \mathrm{a} / \mathrm{m} 2)$ and the vacA s1b allele in $8 / 41 \mathrm{H}$. pylori strains $(5 \mathrm{~s} 1 \mathrm{~b} / \mathrm{ml}, 3 \mathrm{~s} 1 \mathrm{~b} / \mathrm{m} 2)$. The remaining $18(43.9 \%)$ isolates harbored the $v a c A \mathrm{~s} 2 / \mathrm{m} 2$ allele. The predominance of the $v a c A$ s1 allele found in this study is congruent with results from other European studies $[11,37-39,44,45]$. 

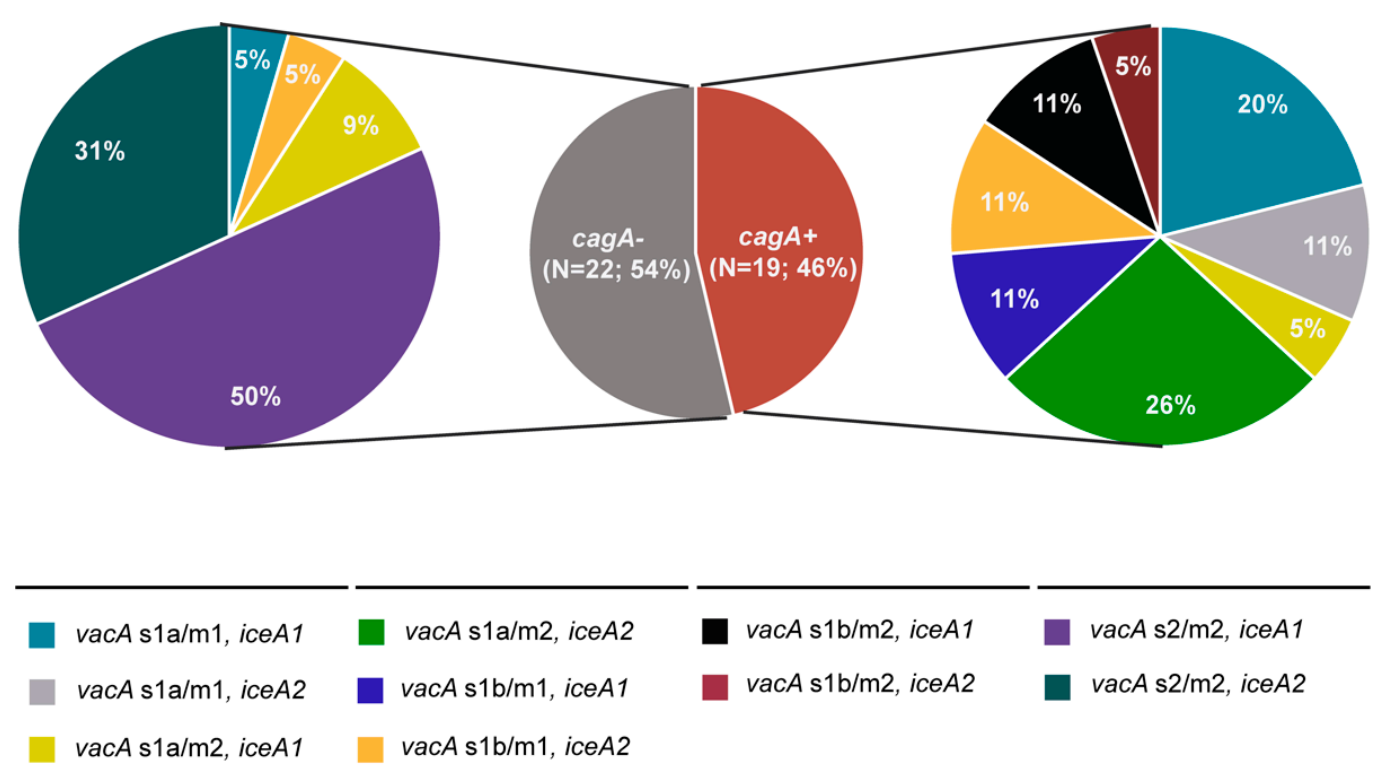

Figure 2. Determination of the presence of $\operatorname{cag} A, v a c A$ and ice $A$ in 41 H. pylori strains isolated from patients with non-atrophic gastritis.

Recent studies have reported an association between the presence of $\operatorname{cag} A$ and the vacA s1 allele in $H$. pylori $[6,9,46]$. In accordance with these findings, all cag $A$-positive $H$. pylori strains harbored either the $v a c A$ s1a or s1b allele $(6 \mathrm{~s} 1 \mathrm{a} / \mathrm{m} 1,6 \mathrm{~s} 1 \mathrm{a} / \mathrm{m} 2,4 \mathrm{~s} 1 \mathrm{~b} / \mathrm{m} 1$ and $3 \mathrm{~s} 1 \mathrm{~b} / \mathrm{m} 2$; Figure 2$)$ in this study $\left(\mathrm{X}^{2}=24.489, P<0.001\right)$. Among the vacA s1 alleles, vacA s1/m1 has been found to be more toxic for epithelial cells than $v a c A s 1 / \mathrm{m} 2$ [47], and has been therefore associated with benign ulcers disease and a higher risk for gastric cancer development [11,39,48-50]. In contrast, vacA s2/m2 strains are virtually nontoxic [3], and therefore, are rarely associated with gastrointestinal pathology $[6,9,19]$. In accordance, none of the $19 \mathrm{cag} A$-positive $H$. pylori strains harbored the vacA s2 allele (Figure 2).

In all $41 \mathrm{H}$. pylori strains, ice $A$ was detected. The ice $A 1$ allele was identified in 23/41 (56.1\%) and the iceA2 allele in 18/41 (43.9\%) H. pylori isolates (Figure 2). This finding is in accordance with other studies from European countries that reported on a predominance of iceA1-positive H. pylori strains in adult gastritis patients (e.g., [38,51,52]). The role of $i c e A$ and its contribution to gastrointestinal disease is somewhat controversial. Two reports suggested an association of iceA1 with higher acute inflammation of the gastric mucosa and ulcers disease $[10,11]$, while other studies could not confirm the association of iceA1 with clinically relevant disease (e.g., $[53,54])$. This is in line with our observation that iceA1 and iceA2 were equally distributed (9 iceA1 vs 10 iceA2) among the 19 cagA-positive H. pylori isolates $(P>0.05$; Figure 2).

The dupA gene was detected in 10/41 (24.4\%) H. pylori isolates. Previous studies suggested its association with enhanced gastric inflammation, which could be due to $d u p A$-mediated induction of proinflammatory cytokine secretion by mononuclear cells [12,15]. Thus, DupA appears to act similar to other proinflammatory virulence factors, including factors encoded by the cag-pathogenicity island and OipA $[13,14,55]$. Interestingly, H. pylori strains lacking dupA have been associated with an increased risk of developing duodenal ulcers or gastric cancer $[15,16]$. In this study, dupA was not more prevalent in cagA-positive than cagA-negative $H$. pylori strains $(P>0.05)$. In line with our results, Zhang et al. [56] found no association between the presence of $\operatorname{dup} A$ and $c a g A, v a c A$, ice $A$ and $b a b A$ alleles. This is in contrast to recent findings indicating a close association between $\operatorname{cag} A$ and $v a c A s 1 / \mathrm{m} 1$, respectively, and $\operatorname{dup} A$ in patients with chronic gastritis or duodenal ulcers [57-59].

Moreover, we determined the association between the presence of $\operatorname{cag} A, v a c A$, ice $A$ and $\operatorname{dup} A$ and the grade of gastritis and $H$. pylori abundance in the gastric mucosa, respectively. Cag $A$ was more abundant in $H$. pylori strains from gastritis patients with moderate or marked gastritis and patients that had a dense H. pylori colonization in the gastric mucosa $(P<0.01$; Figure 3$)$. For vacA allele s1, a 
significant association was only found with the severity of gastritis $(P<0.01)$, while vacA s1 was not significantly more prevalent in the gastric mucosa of patients with highly abundant $H$. pylori $(P=0.08)$. Nevertheless, a trend towards higher vacA s1 prevalence in $H$. pylori strains from gastric biopsies with dense $H$. pylori colonization could be observed. In contrast, neither the presence of $\operatorname{dup} A$ nor the presence of iceA1 in $H$. pylori was associated with more severe gastritis or more dense H. pylori colonization in the gastric mucosa $(P>0.05$; Figure 3$)$.
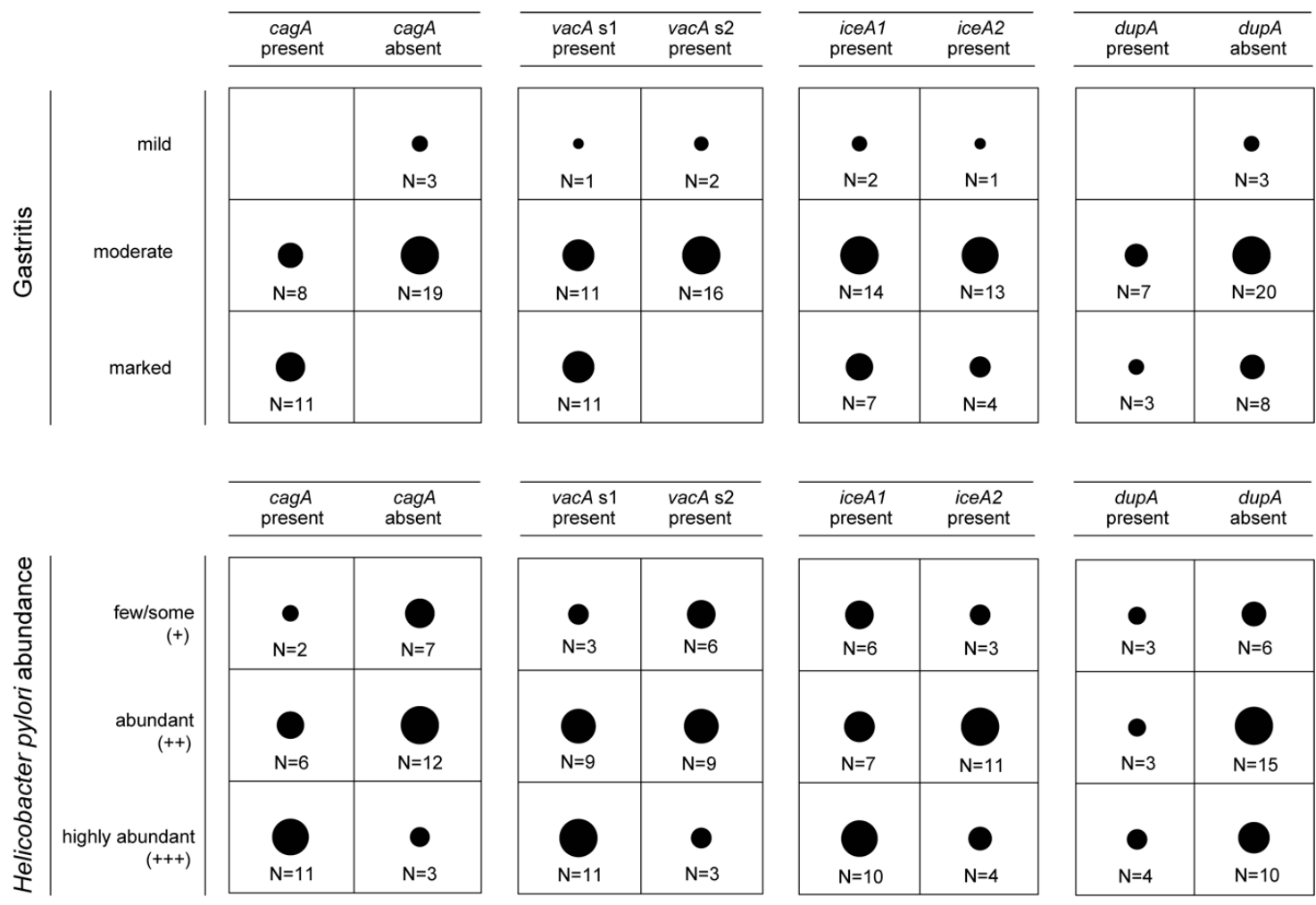

Figure 3. Assessment of the association between the presence of $\operatorname{cag} A, v a c A$, ice $A$ and $d u p A$ and the severity of gastritis and H. pylori abundance in gastric biopsy specimens.

Next, we investigated if more virulent $H$. pylori strains (i.e., strains carrying cagA and/or vac $A$ s1) would be associated with clarithromycin resistance. Both virulence factors, $c a g A$ and $v a c A$ s1, were not associated with clarithromycin resistance $(P>0.05$; Table S3).

\subsection{Presence of Genes Encoding OMPs in H. pylori Isolates}

OMP-mediated attachment to the gastric epithelium is crucial for the establishment of H. pylori associated infection and protects the pathogen from gastric acidity, as well as from displacement due to peristalsis. Sequence analysis of OMP encoding genes, specifically the CT-dinucleotide repeats at their 5 '-ends, elicits their expression status (i.e., in-frame genes are expressed "status-on" and out-of-frame genes are not expressed "status-off").

In-frame variants of $s a b A$ and $s a b B$ were found in $16 / 41$ (39.0\%) and 18/41 (43.9\%) H. pylori isolates, respectively ("status-on"; Table 2). Expression of sabA has been found to be associated with an increased risk of chronic gastric inflammation, intestinal metaplasia, corpus atrophy and even gastric cancer [13,60,61]. A study by Mahadavi et al. [61] suggested that the presence of $s a b A$ is closely related to the presence of the cag-pathogenicity island and $b a b A$.

However, subsequent studies could not confirm this association [62-64]. Congruently, in the present study, in-frame $s a b A$ and $s a b B$ genes were not more prevalent in $c a g A$-positive than in cagA-negative $H$. pylori strains $(P>0.05$; Table 2$)$. 
Table 2. Analysis of outer membrane protein encoding genes and their phase variations in $41 \mathrm{H}$. pylori strains isolated from patients with non-atrophic gastritis.

\begin{tabular}{|c|c|c|c|c|c|}
\hline \multirow{2}{*}{ Gene } & \multicolumn{2}{|c|}{ cagA-positive H. pylori } & \multicolumn{2}{|c|}{ cagA-negative $H$. pylori } & \multirow{2}{*}{$\begin{array}{c}\text { Difference between } \\
\text { cagA-positive and } \\
\text { cagA-negative } H \text {. pylori strains }\end{array}$} \\
\hline & $\begin{array}{c}\text { In-frame } \\
\text { ("status-on") }\end{array}$ & $\begin{array}{l}\text { Out-of-frame } \\
\text { ("status-off") }\end{array}$ & $\begin{array}{c}\text { In-frame } \\
\text { ("status-on") }\end{array}$ & $\begin{array}{l}\text { Out-of-frame } \\
\text { ("status-off") }\end{array}$ & \\
\hline hopZ & 9 & 10 & 13 & 9 & $P>0.05$ \\
\hline oipA & 14 & 5 & 6 & 16 & $P<0.001$ \\
\hline$s a b A$ & 10 & 9 & 6 & 16 & $P>0.05$ \\
\hline$s a b B$ & 10 & 9 & 8 & 14 & $P>0.05$ \\
\hline
\end{tabular}

The gene hopZ was expressed (in-frame gene; "status-on") in 22/41 (53.7\%) H. pylori strains. Accordingly, a study investigating HopZ expression in non-atrophic gastritis patients found hopZ "status-on" in 59\% of patients [65]. HopZ is involved in adhesion to gastric epithelial cells [66,67], thereby providing $H$. pylori with a competitive fitness advantage for attachment to the gastric mucosa and initiation of infection $[65,68]$. However, HopZ was expressed in both, cagA-positive and negative H. pylori strains $(P>0.05$; Table 2$)$. Likewise, previous studies, found no correlation between HopZ expression (in-frame gene; "status-on") and the presence of cagA [69]. Interestingly, a recent study demonstrated that patients infected with $H$. pylori strains harboring a combination of virulence factors, namely the ice $A 1$ allele, sabA "status-on" and hopZ "status-off", had a 10 fold higher risk for developing a mucosa-associated lymphoid tissue (MALT) lymphoma [62], whereas hopZ status has not been found to correlate with the development of atrophic gastritis [65]. In this study, we identified $5 \mathrm{H}$. pylori strains with this specific combination of virulence factors (i.e., ice $A 1$ allele, sabA "status-on" and hopZ "status-off"; Table S1).

Analysis of the oipA sequence of the $41 \mathrm{H}$. pylori isolates identified in-frame variants in 20 strains $(48.8 \%)$. OipA has been suggested to act as a disease-promoting factor, since expression of oipA correlates with increased production of interleukins (IL)-6, IL-8 and IL-11 [55,70]. In addition, OipA has been shown to mediate changes in motility, cytoskeletal reorganization and elongation of gastric epithelial cells by activation of the focal adhesion kinase [71]. These changes in host cells caused by the pathogen are ultimately important to establish infection. Thus, expression of oipA has been related to the development of gastrointestinal pathology including gastric cancer [13,55]. Clinical H. pylori isolates expressing OipA have been frequently found to additionally carry cag $A$ and/or vac $A$ s1 $[13,55,72]$. Concordantly, OipA expression (i.e., "status-on") predominantly occurred in cagA-positive H. pylori strains ( $X^{2}=7.03, P<0.001$; Table 2). Interestingly, H. pylori strains of East Asian origin have been found to exclusively harbor an in-frame oipA gene [55,72]. Congruently, the hspEAsia strain isolated from a gastritis patient with Chinese ethnicity expressed OipA, and additionally carried cagA and vacA s1 (Table 3).

Table 3. The combination of virulence factors in seven presumably highly virulent $H$. pylori strains.

\begin{tabular}{|c|c|c|c|c|c|c|c|c|c|c|c|c|c|c|}
\hline Patient & Age & Sex & Ethnicity & $\operatorname{cag} A$ & vacA & iceA & $b a b A$ & $b a b B$ & $d u p A$ & hopZ & oipA & $s a b A$ & $s a b B$ & hopQ \\
\hline 1 & 31 & $\mathrm{~F}$ & Caucasian & + & $\mathrm{s} 1 \mathrm{a} / \mathrm{m} 1$ & iceA1 & $b a b A 2$ & $b a b B 2$ & - & off & on & on & off & allele 1 \\
\hline 2 & 50 & M & Caucasian & + & $\mathrm{s} 1 \mathrm{a} / \mathrm{m} 2$ & iceA2 & $b a b A 2$ & $b a b B 2$ & - & on & on & off & off & allele 1 \\
\hline 3 & 28 & M & Chinese & + & $\mathrm{s} 1 \mathrm{a} / \mathrm{m} 2$ & iceA1 & $b a b A 2$ & - & - & off & on & on & on & allele 1 \\
\hline 5 & 54 & M & Caucasian & + & $\mathrm{s} 1 \mathrm{a} / \mathrm{m} 1$ & iceA1 & $b a b A 2$ & - & - & on & on & on & on & allele 1 \\
\hline 6 & 54 & M & Caucasian & + & $\mathrm{s} 1 \mathrm{~b} / \mathrm{m} 1$ & iceA2 & $b a b A 2$ & $b a b B 1$ & & off & on & off & on & allele 2 \\
\hline 7 & 50 & $\mathrm{~F}$ & Caucasian & + & $\mathrm{s} 1 \mathrm{~b} / \mathrm{m} 1$ & iceA2 & $b a b A 2$ & - & + & off & off & off & off & allele 2 \\
\hline
\end{tabular}

"on" indicates in-frame genes that are expressed; "off" indicates out-off-frame genes that are not expressed.

The gene encoding the OMP HopQ was present in all H. pylori isolates. Among the $41 \mathrm{H}$. pylori isolates, hop $Q$ allele 1 was found in ten strains $(24.4 \%)$ that all were $\operatorname{cag} A$-positive. Hop $Q$ allele 2 was identified in the remaining $31 \mathrm{H}$. pylori isolates ( $75.6 \%$; 9 cagA-positive, 22 cag $A$-negative). These findings clearly indicate a positive association between $h o p Q$ allele 1 and the presence of cag $A$ in $H$. pylori $\left(X^{2}=12.59, P<0.001\right)$. This is congruent with the notion that hop $Q$ allele 1 is required for maximal 
activity of the Cag-secretion system in H. pylori [73]. In addition, hop $Q$ allele 1 has been associated with more invasive disease and associated with an increased risk for gastric cancer development [13].

Furthermore, we determined the association between the presence of hop $Q$ alleles, the expression of hopZ, oipA, sabA and $s a b B$ and the grade of gastritis and H. pylori abundance in the gastric mucosa, respectively.

$H o p Q$ allele 1 was more abundant in $H$. pylori strains from gastritis patients with moderate or marked gastritis $(P<0.01)$, but was not significantly more prevalent in the gastric mucosa of patients with highly abundant $H$. pylori $(P=0.39$; Tables $S 4$ and S5). Expression of oipA was increased in patients with moderate or marked gastritis, but the difference was statistically not significant $(P=0.06)$. Expression of hopZ, sabA and $s a b B$ was neither associated with the grade of gastritis nor the abundance of H. pylori in the gastric mucosa ( $P>0.05$; Tables $\mathrm{S} 4$ and S5).

Finally, the $41 \mathrm{H}$. pylori isolates were analyzed with respect to the prevalence of the recently defined allele groups of $b a b A$ (AD1 to AD5) and $b a b B$ (BD1 to BD3) [20]. In total, 15/41 H. pylori isolates carried $b a b A / b a b B, 5 / 41$ only $b a b A, 17 / 41$ only $b a b B$, and $4 / 41 H$. pylori strains neither carried $b a b A$ nor $b a b B$ (Figure 4). Seven $c a g A$-positive H. pylori strains with vacA s1 alleles, additionally carried the $b a b A 2$ allele (Figure 4; Table 3). BabA2 has been previously associated with gastrointestinal pathology $[60,74]$. Moreover, other $b a b A$ alleles were also found in cagA-positive $H$. pylori strains (babA1, babA3, babA4, $b a b A 5 ; N=10$; Figure 4). Interestingly, in only three out of $22 \mathrm{cag} A$-negative $H$. pylori strains, $b a b A$ was found (1x babA2 and 2x babA5; Figure 4). When we analyzed the association of $v a c A$ and $b a b A$ alleles, we found different $b a b A$ alleles in $H$. pylori strains with vac $A \mathrm{~s} 1$, whereas, $b a b A 5$ was present in only one of $18 \mathrm{H}$. pylori strains with a vacA s2/m2 allele (Figure 4).

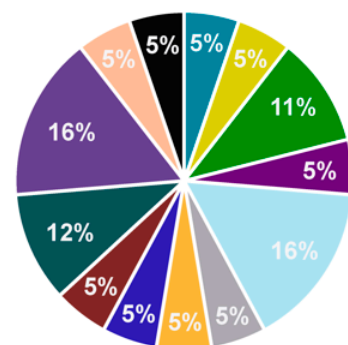

$\operatorname{cag} A+(\mathrm{N}=19)$

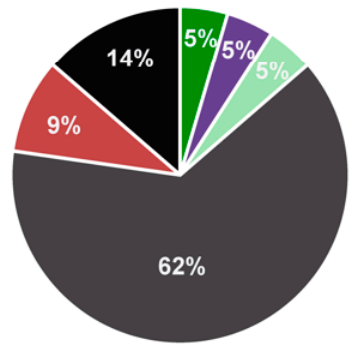

$\operatorname{cag} A-(\mathrm{N}=22)$

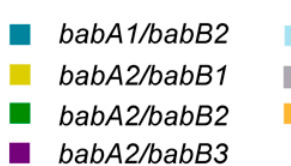

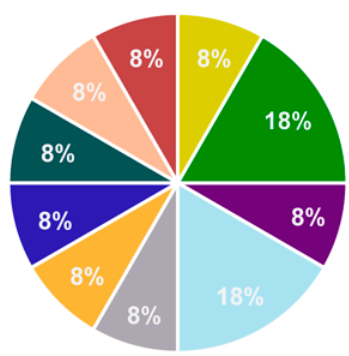

$\operatorname{vac} A \mathrm{~s} 1 \mathrm{a} / \mathrm{m} 1(\mathrm{~N}=7)$ $\operatorname{vac} A \mathrm{~s} 1 \mathrm{~b} / \mathrm{m} 1(\mathrm{~N}=5)$

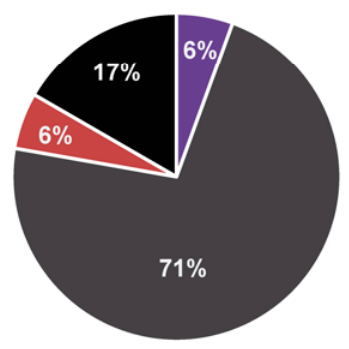

$\operatorname{vac} A \mathrm{~s} 2 / \mathrm{m} 2(\mathrm{~N}=18)$

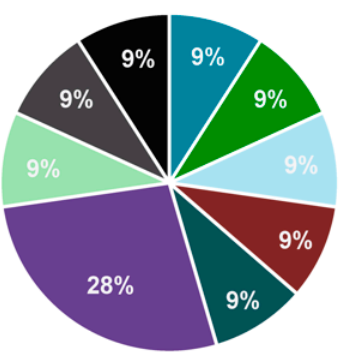

$\operatorname{vac} A \mathrm{~s} 1 \mathrm{a} / \mathrm{m} 2(\mathrm{~N}=8)$ $\operatorname{vac} A \mathrm{~s} 1 \mathrm{~b} / \mathrm{m} 2(\mathrm{~N}=3)$

Figure 4. Determination of the presence of different $b a b A$ and $b a b B$ alleles and their association with $\operatorname{cag} A$ and vac $A$ in $41 \mathrm{H}$. pylori strains isolated from patients with non-atrophic gastritis.

\subsection{Presence of Multiple Virulence Determinants and OMPs in H. pylori Isolates}

In this study, seven of $41 \mathrm{H}$. pylori strains carried multiple virulence factors, namely cag $A, v a c A$ s1 and $b a b A 2$, whereas four of them additionally carried the hop $Q$ allele 1 and expressed OipA, SabA 
and SabB (Table 3). The presence of specific virulence factors and expression of certain OMPs in H. pylori (i.e., $c a g A, v a c A$ s1 and $b a b A 2$ ) has been reported to have multiple effects on patients, such as (i) increased H. pylori density in the gastric mucosa [69], (ii) increased gastric inflammation and epithelial damage [49], and (iii) severity of $H$. pylori associated disease and development of peptic ulcers, gastric cancer and MALT lymphoma [49,60,62].

Moreover, geographic differences in the prevalence of virulence factors in $H$. pylori have been observed. In nearly all East Asian $H$. pylori isolates, strain-specific features linked to high gastric cancer risk (including the presence of $c a g A, v a c A s 1 / \mathrm{m} 1$ and $b a b A 2$ ) have been detected $[45,75,76]$. In our patient population, only one patient with Chinese ethnicity was infected with a $H$. pylori isolate belonging to hspEAsia. The isolate carried cagA, vacA s1, iceA1, babA2, hopQ allele 1 and expressed OipA, SabA and SabB (Table 3). The predominance of strains harboring cagA, vacA s1/m1, and other strain-specific markers linked to gastric cancer may be one of the factors contributing to the high gastric cancer rate in East Asia. Congruently, H. pylori strains harboring few or none of these features have been reported to be less frequently associated with gastrointestinal pathology. CagA-negative $H$. pylori strains containing $v a c A$ s2 alleles and lacking $b a b A$ are commonly found in the United States and Western Europe [3,45], and were found in the majority of our patient population.

Our study has several limitations: It was designed as a single center laboratory-based study using clinical H. pylori strains isolated from patients with non-atrophic gastritis. As Switzerland is a low prevalence country for gastric cancer, we could just include H. pylori strains from non-atrophic gastritis patients in this study. H. pylori strains exhibit a high degree of heterogeneity that supports the bacteria's adaptation to and persistence in the gastric mucosa. Thus, some technical issues must be considered: First, multiple gastric biopsy specimens should be used for H. pylori culture in order to enhance sensitivity and detect $H$. pylori sub-populations. Second, multiple colonies should be picked from agar plates for DNA extraction and library preparation to not miss sub-populations. Third, H. pylori strains should be sequenced with sufficient coverage to detect all heterogeneity in the H. pylori population. Moreover, we had a rather small patient population $(\mathrm{N}=41)$. Consequently, we may have not been able to detect a statistically significant association between the presence of some virulence factors or their expression and the grade of gastritis as well as H. pylori abundance in the gastric mucosa. Thus, this association should be investigated in future studies in bigger patient cohorts.

\section{Conclusion}

In this study, we investigated the epidemiology of H. pylori and the presence of virulence genes in $H$. pylori strains isolated from 41 Swiss patients with non-atrophic gastritis. It has been previously reported that genetic determinants in the $H$. pylori genome and host factors play and important role in determining the clinical outcome of the H. pylori associated infection and the progression to more severe gastrointestinal pathology [1,2]. To evaluate if patients in our patient population may have an increased risk to develop more severe $H$. pylori associated disease, a WGS-based molecular analyses of $H$. pylori isolates in order to assess their virulence factor profiles was performed. H. pylori strains that carried $\operatorname{cag} A$, vac $A$ s 1 and hop $Q$ allele 1 were more abundant in patients with pronounced gastritis (grade moderate or marked) and led to more dense colonization in the gastric mucosa of these patients (i.e., $H$. pylori was abundant $(++)$ or highly abundant $(+++)$ ). However, cagA and vacA s1 factors were not associated with drug resistance indicating that more virulent strains are not necessarily drug resistant. Moreover, we identified seven patients among our 41 patients that were infected with $H$. pylori strains that carried a combination of virulence factors reported to be associated with a higher risk for developing severe gastrointestinal pathology like duodenal ulcers and even gastric cancer. Current guidelines recommend to eradicate $H$. pylori in all individuals, even in patients with asymptomatic H. pylori gastritis [77]. To this end, next generation sequencing technology may be employed in clinical diagnostic laboratories for rapid monitoring of virulence determinants in H. pylori and assessment of an isolate's pathogenic potential. This thorough characterization of $H$. pylori offers tremendous opportunities to improve individualized prognostic assessment, counselling, and follow-up care for 
patients. This could ultimately lead to a more personalized treatment and management of patients suffering from $H$. pylori associated infections.

Supplementary Materials: The following are available online at http://www.mdpi.com/2077-0383/8/7/1030/s1, Table S1: Summary of demographic patient information, endoscopic data and overview of virulence factors and phenotypic antibiotic resistance information of the H. plori isolates; virulence factors: a grey background indicates the presence of a virulence gene or that the virulence gene is expressed ("status-on"); antibiotic resistance information: a red background indicates resistance of $H$. pylori to the respective antibiotic. MIC, minimum inhibitory concentration, Table S2: Gene sequences derived from $H$. pylori strains available in the NCBI database used to detect the presence and variants of different virulence genes in the $41 \mathrm{H}$. pylori strains isolated from non-atrophic gastritis patients, Table S3: Association between the presence of $c a g A$ and vacA alleles and clarithromycin resistance, Table S4: Association between the abundance of Helicobacter pylori in the gastric mucosa and the expression of outer membrane proteins, Table S5: Association between the grade of gastritis and the expression of outer membrane proteins in Helicobacter pylori.

Author Contributions: F.N.L., F.I., P.M.K., D.P., and K.W. designed the study. F.N.L., P.L., R.Z. and K.W. were responsible for the microbiological work-up of the samples. F.N.L., F.I., P.M.K., P.L., F.V., J.Q., D.P., and K.W. did the data mining and analyzed the data. F.N.L., F.I., P.M.K., and K.W. wrote the initial draft of the manuscript. All authors reviewed and edited the manuscript.

Funding: This study was funded by the Institute of Medical Microbiology, University of Zurich.

Acknowledgments: We thank the technicians of the Institute of Medical Microbiology for expert help and assistance, especially Susanne Blasowitsch and Valeria Pereira Pires. We thank the Institute of Medical Microbiology, University of Zurich, for continuous support. Filipa F. Vale is recipient of a postdoctoral fellowship (SFRH/BPD/95125/2013) from the Fundação para a Ciência e a Tecnologia (FCT).

Availability of Data and Material: Whole genome sequences of the H. pylori strains analyzed in this study are available on NCBI under accession numbers: RJHB00000000, RJFC00000000, RJFY00000000, RJGH00000000, RJGK00000000, RJGL00000000, RJGO00000000, RJGV00000000, RJGY00000000, RJHA00000000, RJHC00000000, RJHD00000000, RJHF00000000, RJHG00000000, RJHL00000000, RJHM00000000, RJHR00000000, RJHT00000000, RJHU00000000, RJHW00000000, RJHX00000000, RJIA00000000, RJIC00000000, RJID00000000, RJIE00000000, RJIH00000000, RJII00000000, RJIJ00000000, RJIK00000000, RJIL00000000, RJIO00000000, RJIP00000000, RJIQ00000000, RJIR00000000, RJIS00000000, RJIU00000000, RJIV00000000, RJIW00000000, RJIY00000000.

Conflicts of Interest: The authors declare no conflict of interest.

\section{References}

1. Wroblewski, L.E.; Peek, R.M.; Wilson, K.T. Helicobacter pylori and gastric cancer: Factors that modulate disease risk. Clin. Microbiol. Rev. 2010, 23, 713-739. [CrossRef] [PubMed]

2. Jonaitis, L.; Pellicano, R.; Kupcinskas, L. Helicobacter pylori and nonmalignant upper gastrointestinal diseases. Helicobacter 2018. [CrossRef] [PubMed]

3. Atherton, J.C.; Cao, P.; Peek, R.M.; Tummuru, M.K.; Blaser, M.J.; Cover, T.L. Mosaicism in vacuolating cytotoxin alleles of Helicobacter pylori association of specific vacA types with cytotoxin production and peptic ulceration. J. Biol. Chem. 1995, 270, 17771-17777. [CrossRef] [PubMed]

4. Blaser, M.J.; Perez-Perez, G.I.; Kleanthous, H.; Cover, T.L.; Peek, R.M.; Chyou, P.; Stemmermann, G.N.; Nomura, A. Infection with Helicobacter pylori strains possessing cagA is associated with an increased risk of developing adenocarcinoma of the stomach. Cancer Res. 1995, 55, 2111-2115. [PubMed]

5. Censini, S.; Lange, C.; Xiang, Z.; Crabtree, J.E.; Ghiara, P.; Borodovsky, M.; Rappuoli, R.; Covacci, A. Cag, a pathogenicity island of Helicobacter pylori, encodes type I-specific and disease-associated virulence factors. Proc. Natl. Acad. Sci. USA 1996, 93, 14648-14653. [CrossRef] [PubMed]

6. Atherton, J.C. The pathogenesis of Helicobacter pylori induced gastro-duodenal diseases. Annu. Rev. Pathol. 2006, 1, 63-96. [CrossRef] [PubMed]

7. Camilo, V.; Sugiyama, T.; Touati, E. Pathogenesis of Helicobacter pylori infection. Helicobacter 2017, 22. [CrossRef] [PubMed]

8. Greenfield, L.K.; Jones, N.L. Modulation of autophagy by Helicobacter pylori and its role in gastric carcinogenesis. Trends Microbiol. 2013, 21, 602-612. [CrossRef] [PubMed]

9. Atherton, J.; Peek, R., Jr.; Tham, K.; Cover, T.; Blaser, M. Clinical and pathological importance of heterogeneity in vacA, the vacuolating cytotoxin gene of Helicobacter pylori. Gastroenterology 1997, 112, 92-99. [CrossRef] 
10. Peek, J.R.; Thompson, S.A.; Donahue, J.P.; Tham, K.T.; Atherton, J.C.; Blaser, M.J.; Miller, G.G. Adherence to gastric epithelial cells induces expression of a Helicobacter pylori gene, iceA, that is associated with clinical outcome. Proc. Assoc. Am. Phys. 1998, 110, 531-544. [PubMed]

11. van Doorn, L.J.; Figueiredo, C.; Sanna, R.; Plaisier, A.; Schneeberger, P.; de Boer, W.; Quint, W. Clinical relevance of the cagA, vacA, and iceA status of Helicobacter pylori. Gastroenterology 1998, 115, 58-66. [CrossRef]

12. Hussein NR, Argent RH, Marx CK, Patel SR, Robinson K, Atherton JC: Helicobacter pylori dupA is polymorphic, and its active form induces proinflammatory cytokine secretion by mononuclear cells. J. Infect. Dis. 2010, 202, 261-269. [CrossRef] [PubMed]

13. Yamaoka, Y.; Ojo, O.; Fujimoto, S.; Odenbreit, S.; Haas, R.; Gutierrez, O.; El-Zimaity, H.M.; Reddy, R.; Arnqvist, A.; Graham, D.Y. Helicobacter pylori outer membrane proteins and gastroduodenal disease. Gut 2006, 55, 775-781. [CrossRef] [PubMed]

14. Ando, T.; Peek, R.M.; Lee, Y.C.; Krishna, U.; Kusugami, K.; Blaser, M.J. Host cell responses to genotypically similar Helicobacter pylori isolates from United States and Japan. Clin. Diagn. Lab. Immunol. 2002, 9, 167-175. [CrossRef] [PubMed]

15. Lu, H.; Hsu, P.I.; Graham, D.Y.; Yamaoka, Y. Duodenal ulcer promoting gene of Helicobacter pylori. Gastroenterology 2005, 128, 833-848. [CrossRef]

16. Abadi, A.T.B.; Taghvaei, T.; Wolfram, L.; Kusters, J.G. Infection with Helicobacter pylori strains lacking dupA is associated with an increased risk of gastric ulcer and gastric cancer development. J. Med. Microbiol. 2012, 61, 23-30. [CrossRef] [PubMed]

17. Tomb, J.F.; White, O.; Kerlavage, A.R.; Clayton, R.A.; Sutton, G.G.; Fleischmann, R.D.; Ketchum, K.A.; Klenk, H.P.; Gill, S.; Dougherty, B.A. The complete genome sequence of the gastric pathogen Helicobacter pylori. Nature 1997, 388, 539-547. [CrossRef] [PubMed]

18. Alm, R.A.; Ling, L.S.L.; Moir, D.T.; King, B.L.; Brown, E.D.; Doig, P.C.; Smith, D.R.; Noonan, B.; Guild, B.C.; Carmel, G. Genomic-sequence comparison of two unrelated isolates of the human gastric pathogen Helicobacter pylori. Nature 1999, 397, 176-180. [CrossRef]

19. Cover, T.L. Helicobacter pylori diversity and gastric cancer risk. MBio 2016, 7, e01869-15. [CrossRef]

20. Pride, D.T.; Meinersmann, R.J.; Blaser, M.J. Allelic variation within Helicobacter pylori babA and $b a b B$. Infect. Immun. 2001, 69, 1160-1171. [CrossRef]

21. Lauener, F.; Imkamp, F.; Lehours, P.; Buissonnière, A.; Benejat, L.; Zbinden, R.; Keller, P.; Wagner, K. Genetic determinants and prediction of antibiotic resistance phenotypes in Helicobacter pylori. J. Clin Med. 2019, 8, 53. [CrossRef] [PubMed]

22. Dixon, M.F.; Genta, R.M.; Yardley, J.H.; Correa, P. Classification and grading of gastritis: The updated Sydney system. Am. J. Surg. Pathol. 1996, 20, 1161-1181. [CrossRef] [PubMed]

23. McFarland, J. The nephelometer: An instrument for estimating the number of bacteria in suspensions used for calculating the opsonic index and for vaccines. JAMA 1907, 49, 1176-1178. [CrossRef]

24. EUCAST. Breakpoint Tables for Interpretation of MICs and Zone Diameters, Version 9.0. 2019. Available online: http://www.eucast.org (accessed on 1 January 2019).

25. Hays, C.; Burucoa, C.; Lehours, P.; Tran, C.T.; Leleu, A.; Raymond, J. Molecular characterization of Helicobacter pylori resistance to rifamycins. Helicobacter 2018, 23. [CrossRef] [PubMed]

26. CASFM/EUCAST. Breakpoint Tables for Interpretation of MICs and Zone Diameters, Version 1.0. 2019. Available online: www.sfm-microbiologie.org (accessed on 3 January 2019).

27. Hunt, M.; Mather, A.E.; Sánchez-Busó, L.; Page, A.J.; Parkhill, J.; Keane, J.A.; Harris, S.R. ARIBA: Rapid antimicrobial resistance genotyping directly from sequencing reads. Microb. Genom. 2017, 3. [CrossRef] [PubMed]

28. R Development Core Team. R: A Language and Environment for Statistical Computing; R Foundation for Statistical Computing: Vienna, Austria, 2018; ISBN 3-900051-07-0. Available online: http://www.R-project.org (accessed on 12 July 2019).

29. Falush, D.; Wirth, T.; Linz, B.; Pritchard, J.K.; Stephens, M.; Kidd, M.; Blaser, M.J.; Graham, D.Y.; Vacher, S.; Perez-Perez, G.I. Traces of human migrations in Helicobacter pylori populations. Science 2003, 299, 1582-1585. [CrossRef] [PubMed]

30. Tamura, K.; Stecher, G.; Peterson, D.; Filipski, A.; Kumar, S. MEGA6: Molecular evolutionary genetics analysis version 6.0. Mol. Biol. Evol. 2013, 30, 2725-2729. [CrossRef] [PubMed] 
31. Pritchard, J.K.; Stephens, M.; Donnelly, P. Inference of population structure using multilocus genotype data. Genetics 2000, 155, 945-959. [PubMed]

32. Falush, D.; Stephens, M.; Pritchard, J.K. Inference of population structure using multilocus genotype data: Linked loci and correlated allele frequencies. Genetics 2003, 164, 1567-1587. [PubMed]

33. Malfertheiner, P.; Megraud, F.; O'morain, C.; Gisbert, J.; Kuipers, E.; Axon, A.; Bazzoli, F.; Gasbarrini, A.; Atherton, J.; Graham, D. Management of Helicobacter pylori infection—-the Maastricht V/Florence consensus report. Gut 2017, 66, 6-30. [CrossRef] [PubMed]

34. Wagner, K.; Imkamp, F.; Pires, V.; Keller, P. Evaluation of Lightmix Mycoplasma macrolide assay for detection of macrolide-resistant Mycoplasma pneumoniae in pneumonia patients. Clin. Microbiol. Infect. 2019, 25. [CrossRef] [PubMed]

35. Oleastro, M.; Rocha, R.; Vale, F.F. Population genetic structure of Helicobacter pylori strains from Portuguese-speaking countries. Helicobacter 2017, 22. [CrossRef] [PubMed]

36. Thorell, K.; Yahara, K.; Berthenet, E.; Lawson, D.J.; Mikhail, J.; Kato, I.; Mendez, A.; Rizzato, C.; Bravo, M.M.; Suzuki, R. Rapid evolution of distinct Helicobacter pylori subpopulations in the Americas. PLoS Genet. 2017, 13. [CrossRef] [PubMed]

37. Figueiredo, C.; Van Doorn, L.J.; Nogueira, C.; Soares, J.; Pinho, C.; Figueira, P.; Quint, W.; Carneiro, F. Helicobacter pylori genotypes are associated with clinical outcome in Portuguese patients and show a high prevalence of infections with multiple strains. Scand. J. Gastroenterol. 2001, 36, 128-135. [CrossRef] [PubMed]

38. Erzin, Y.; Koksal, V.; Altun, S.; Dobrucali, A.; Aslan, M.; Erdamar, S.; Dirican, A.; Kocazeybek, B. Prevalence of Helicobacter pylori vacA, cagA, cagE, iceA, babA2 genotypes and correlation with clinical outcome in Turkish patients with dyspepsia. Helicobacter 2006, 11, 574-580. [CrossRef] [PubMed]

39. Miehlke, S.; Kirsch, C.; Agha-Amiri, K.; Günther, T.; Lehn, N.; Malfertheiner, P.; Stolte, M.; Ehninger, G.; Bayerdörffer, E. The Helicobacter pylori vacA s1, $\mathrm{m} 1$ genotype and $\operatorname{cag} A$ is associated with gastric carcinoma in Germany. Int. J. Cancer 2000, 87, 322-327. [CrossRef]

40. Heikkinen, M.; Mayo, K.; Megraud, F.; Vornanen, M.; Marin, S.; Pikkarainen, P.; Julkunen, R. Association of CagA-positive and CagA-negative Helicobacter pylori strains with patients' symptoms and gastritis in primary care patients with functional upper abdominal complaints. Scand. J. Gastroenterol. 1998, 33, 31-38.

41. Audibert, C.; Janvier, B.; Grignon, B.; Salaüna, L.; Burucoa, C.; Lecron, J.C.; Fauchère, J.L. Correlation between IL-8 induction, cagA status and vacA genotypes in 153 French Helicobacter pylori isolates. Res. Microbiol. 2000, 15, 191-200. [CrossRef]

42. Chiarini, A.; Calà, C.; Bonura, C.; Gullo, A.; Giuliana, G.; Peralta, S.; D'Arpa, F.; Giammanco, A. Prevalence of virulence-associated genotypes of Helicobacter pylori and correlation with severity of gastric pathology in patients from western Sicily, Italy. Eur. J. Clin. Microbiol. Infect. Dis. 2009, 28, 437. [CrossRef]

43. Boyanova, L.; Markovska, R.; Yordanov, D.; Marina, M.; Ivanova, K.; Panayotov, S.; Gergova, G.; Mitov, I. High prevalence of virulent Helicobacter pylori strains in symptomatic Bulgarian patients. Diagn. Microbiol. Infect. Dis. 2009, 64, 374-380. [CrossRef]

44. Andreson, H.; Loivukene, K.; Sillakivi, T.; Maaroos, H.I.; Ustav, M.; Peetsalu, A.; Mikelsaar, M. Association of cagA and vacA genotypes of Helicobacter pylori with gastric diseases in Estonia. J. Clin. Microbiol. 2002, 40, 298-300. [CrossRef] [PubMed]

45. Van Doorn, L.J.; Figueiredo, C.; Mégraud, F.; Pena, S.; Midolo, P.; Queiroz, D.M.D.M.; Carneiro, F.; Vanderborght, B.; Maria Da Glória, F.P.; Sanna, R. Geographic distribution of vacA allelic types of Helicobacter pylori. Gastroenterology 1999, 116, 823-830. [CrossRef]

46. Yamaoka, Y.; Kodama, T.; Kita, M.; Imanishi, J.; Kashima, K.; Graham, D.Y. Relationship of vacA genotypes of Helicobacter pylori to cagA status, cytotoxin production, and clinical outcome. Helicobacter 1998, 3, 241-253. [CrossRef] [PubMed]

47. Letley, D.P.; Rhead, J.L.; Twells, R.J.; Dove, B.; Atherton, J.C. Determinants of non-toxicity in the gastric pathogen Helicobacter pylori. J. Biol. Chem. 2003, 278, 26734-26741. [CrossRef] [PubMed]

48. Van Doorn, L.; Figueiredo, C.; Rossau, R.; Jannes, G.; Van Asbroeck, M.; Sousa, J.; Carneiro, F.; Quint, W. Typing of Helicobacter pylori vacA gene and detection of cagA gene by PCR and reverse hybridization. J. Clin. Microbiol. 1998, 36, 1271-1276. [PubMed]

49. Figueiredo, C.; Machado, J.C.; Pharoah, P.; Seruca, R.; Sousa, S.; Carvalho, R.; Capelinha, A.F.; Quint, W.; Caldas, C.; van Doorn, L.J. Helicobacter pylori and interleukin 1 genotyping: An opportunity to identify high-risk individuals for gastric carcinoma. J. Natl. Cancer. Inst. 2002, 94, 1680-1687. [CrossRef] [PubMed] 
50. Kidd, M.; Lastovica, A.; Atherton, J.; Louw, J. Heterogeneity in the Helicobacter pylori vacA and cagA genes: Association with gastroduodenal disease in South Africa? Gut 1999, 45, 499-502. [CrossRef]

51. Miehlke, S.; Yu, J.; Schuppler, M.; Frings, C.; Kirsch, C.; Negraszus, N.; Morgner, A.; Stolte, M.; Ehninger, G.; Bayerdörffer, E. Helicobacter pylori vacA, iceA, and $c a g A$ status and pattern of gastritis in patients with malignant and benign gastroduodenal disease. Am. J. Gastroenterol. 2001, 96, 1008-1013. [CrossRef]

52. Boyanova, L.; Yordanov, D.; Gergova, G.; Markovska, R.; Mitov, I. Association of iceA and babA genotypes in Helicobacter pylori strains with patient and strain characteristics. Antonie Van Leeuwenhoek 2010, 98, 343-350. [CrossRef]

53. Yamaoka, Y.; Kodama, T.; Gutierrez, O.; Kim, J.G.; Kashima, K.; Graham, D.Y. Relationship between Helicobacter pylori iceA, $\operatorname{cag} A$, and $v a c A$ status and clinical outcome: Studies in four different countries. J. Clin. Microbiol. 1999, 37, 2274-2279.

54. Nishiya, D.; Shimoyama, T.; Fukuda, S.; Yoshimura, T.; Tanaka, M.; Munakata, A. Evaluation of the clinical relevance of the iceA1 gene in patients with Helicobacter pylori infection in Japan. Scand. J. Gastroenterol. 2000, 35, 36-39. [PubMed]

55. Yamaoka, Y.; Kikuchi, S.; El-Zimaity, H.M.; Gutierrez, O.; Osato, M.S.; Graham, D.Y. Importance of Helicobacter pylori oipA in clinical presentation, gastric inflammation, and mucosal interleukin 8 production. Gastroenterology 2002, 123, 414-424. [CrossRef] [PubMed]

56. Zhang, Z.; Zheng, Q.; Chen, X.; Xiao, S.; Liu, W.; Lu, H. The Helicobacter pylori duodenal ulcer promoting gene, dupA in China. BMC Gastroenterol. 2008, 8. [CrossRef] [PubMed]

57. Pereira, W.N.; Ferraz, M.A.; Zabaglia, L.M.; de Labio, R.W.; Orcini, W.A.; Ximenez, J.P.B.; Neto, A.C.; Payão, S.L.M.; Rasmussen, L.T. Association among H. pylori virulence markers $\operatorname{dup} A, \operatorname{cag} A$ and $\operatorname{vac} A$ in Brazilian patients. J. Venom Anim. Toxins Incl. Trop. Dis. 2014, 20. [CrossRef] [PubMed]

58. Arachchi, H.J.; Kalra, V.; Lal, B.; Bhatia, V.; Baba, C.; Chakravarthy, S.; Rohatgi, S.; Sarma, P.M.; Mishra, V.; Das, B. Prevalence of duodenal ulcer-promoting gene $(d u p A)$ of Helicobacter pylori in patients with duodenal ulcer in North Indian population. Helicobacter 2007, 12, 591-597. [CrossRef] [PubMed]

59. Gomes, L.I.; Rocha, G.A.; Rocha, A.M.; Soares, T.F.; Oliveira, C.A.; Bittencourt, P.F.; Queiroz, D.M. Lack of association between Helicobacter pylori infection with dupA-positive strains and gastroduodenal diseases in Brazilian patients. Int. J. Med. Microbiol. 2008, 298, 223-230. [CrossRef]

60. Gerhard, M.; Lehn, N.; Neumayer, N.; Borén, T.; Rad, R.; Schepp, W.; Miehlke, S.; Classen, M.; Prinz, C. Clinical relevance of the Helicobacter pylori gene for blood-group antigen-binding adhesin. Proc. Natl. Acad. Sci. USA 1999, 96, 12778-12783. [CrossRef] [PubMed]

61. Mahdavi, J.; Sondén, B.; Hurtig, M.; Olfat, F.O.; Forsberg, L.; Roche, N.; Ångström, J.; Larsson, T.; Teneberg, S.; Karlsson, K.A. Helicobacter pylori SabA adhesin in persistent infection and chronic inflammation. Science 2002, 297, 573-578. [CrossRef]

62. Lehours, P.; Ménard, A.; Dupouy, S.; Bergey, B.; Richy, F.; Zerbib, F.; Ruskoné-Fourmestraux, A.; Delchier, J.C.; Mégraud, F. Evaluation of the association of nine Helicobacter pylori virulence factors with strains involved in low-grade gastric mucosa-associated lymphoid tissue lymphoma. Infect. Immun. 2004, 72, 880-888. [CrossRef]

63. De Jonge, R.; Pot, R.G.; Loffeld, R.J.; Van Vliet, A.H.; Kuipers, E.J.; Kusters, J.G. The functional status of the Helicobacter pylori sabB adhesin gene as a putative marker for disease outcome. Helicobacter 2004, 9, 158-164. [CrossRef]

64. Sheu, B.S.; Odenbreit, S.; Hung, K.H.; Liu, C.P.; Sheu, S.M.; Yang, H.B.; Wu, J.J. Interaction between host gastric Sialyl-Lewis $\mathrm{X}$ and H. pylori SabA enhances H. pylori density in patients lacking gastric Lewis B antigen. Am. J. Gastroenterol. 2006, 101, 36-44. [CrossRef] [PubMed]

65. Kennemann, L.; Brenneke, B.; Andres, S.; Engstrand, L.; Meyer, T.F.; Aebischer, T.; Josenhans, C.; Suerbaum, S. In vivo sequence variation in HopZ, a phase-variable outer membrane protein of Helicobacter pylori. Infect. Immun. 2012, 80, 4364-4373. [CrossRef] [PubMed]

66. Peck, B.; Ortkamp, M.; Diehl, K.D.; Hundt, E.; Knapp, B. Conservation, localization and expression of HopZ, a protein involved in adhesion of Helicobacter pylori. Nucleic Acid. Res. 1999, 27, 3325-3333. [CrossRef] [PubMed]

67. Yamaoka, Y.; Kudo, T.; Lu, H.; Casola, A.; Brasier, A.R.; Graham, D.Y. Role of interferon-stimulated responsive element-like element in interleukin-8 promoter in Helicobacter pylori infection. Gastroenterology 2004, 126, 1030-1043. [CrossRef] [PubMed] 
68. Giannakis, M.; Backhed, H.K.; Chen, S.L.; Faith, J.J.; Wu, M.; Guruge, J.L.; Engstrand, L.; Gordon, J.I. The response of gastric epithelial progenitors to Helicobacter pylori isolates obtained from Swedish patients with chronic atrophic gastritis. J. Biol. Chem. 2009, 284, 30383-30394. [CrossRef] [PubMed]

69. Yamaoka, Y.; Kita, M.; Kodama, T.; Imamura, S.; Ohno, T.; Sawai, N.; Ishimaru, A.; Imanishi, J.; Graham, D.Y. Helicobacter pylori infection in mice: Role of outer membrane proteins in colonization and inflammation. Gastroenterology 2002, 123, 1992-2004. [CrossRef] [PubMed]

70. Yamaoka, Y.; Kwon, D.H.; Graham, D.Y. A Mr 34,000 proinflammatory outer membrane protein (oipA) of Helicobacter pylori. Proc. Natl. Acad. Sci. USA 2000, 97, 7533-7538. [CrossRef] [PubMed]

71. Tabassam, F.H.; Graham, D.Y.; Yamaoka, Y. OipA plays a role in Helicobacter pylori-induced focal adhesion kinase activation and cytoskeletal re-organization. Cell. Microbiol. 2008, 10, 1008-1020. [CrossRef]

72. Ando, T.; Peek, R.; Pride, D.; Levine, S.; Takata, T.; Lee, Y.C.; Kusugami, K.; Van der Ende, A.; Kuipers, E.; Kusters, J. Polymorphisms of Helicobacter pylori HP0638 reflect geographic origin and correlate with cagA status. J. Clin. Microbiol. 2002, 40, 239-246. [CrossRef]

73. Belogolova, E.; Bauer, B.; Pompaiah, M.; Asakura, H.; Brinkman, V.; Ertl, C.; Bartfeld, S.; Nechitaylo, T.Y.; Haas, R.; Machuy, N. Helicobacter pylori outer membrane protein HopQ identified as a novel T4SS-associated virulence factor. Cell. Microbiol. 2013, 15, 1896-1912.

74. Yu, J.; Leung, W.; Go, M.; Chan, M.; To, K.; Ng, E.; Chan, F.; Ling, T.; Chung, S.; Sung, J. Relationship between Helicobacter pylori babA2 status with gastric epithelial cell turnover and premalignant gastric lesions. Gut 2002, 51, 480-484. [CrossRef] [PubMed]

75. Ito, Y.; Azuma, T.; Ito, S.; Miyaji, H.; Hirai, M.; Yamazaki, Y.; Sato, F.; Kato, T.; Kohli, Y.; Kuriyama, M. Analysis and typing of the vacA gene from cagA-positive strains of Helicobacter pylori isolated in Japan. J. Clin. Microbiol. 1997, 35, 1710-1714. [PubMed]

76. Lai, C.H.; Kuo, C.H.; Chen, Y.C.; Chao, F.Y.; Poon, S.K.; Chang, C.S.; Wang, W.C. High prevalence of cagA-and babA2-positive Helicobacter pylori clinical isolates in Taiwan. J. Clin. Microbiol. 2002, 40, 3860-3862. [CrossRef] [PubMed]

77. Fischbach, W.; Malfertheiner, P.; Jansen, P.L.; Bolten, W.; Bornschein, J.; Buderus, S.; Glocker, E.; Hoffmann, J.; Koletzko, S.; Labenz, J. S2k-Leitlinie Helicobacter pylori und gastroduodenale Ulkuskrankheit. Zeitschrift für Gastroenterologie 2016, 54, 327-363. [PubMed]

(C) 2019 by the authors. Licensee MDPI, Basel, Switzerland. This article is an open access article distributed under the terms and conditions of the Creative Commons Attribution (CC BY) license (http://creativecommons.org/licenses/by/4.0/). 